\title{
ISCHEMIC COLITIS IN A PATIENT WITH CHRONIC KIDNEY FAILURE: CASE REPORT
}

\author{
Mirela TIGLIS ${ }^{1,2}$, Cristina BOLOGA ${ }^{1}$, Tudor HURMUZACHE ${ }^{1}$, Tiberiu P. NEAGU ${ }^{1,2 \unrhd,}$ \\ Camelia C. DIACONU ${ }^{1,2}$, Ovidiu G. BRATU ${ }^{1,3}$, loana M. GRINTESCU ${ }^{1,2}$ \\ ${ }^{1}$ Clinical Emergency Hospital of Bucharest, Bucharest, Romania \\ ${ }^{2}$ Carol Davila University of Medicine and Pharmacy, Bucharest, Romania \\ ${ }^{3}$ Emergency University Central Military Hospital "Carol Davila", Academy of Romanian Scientists, \\ Bucharest, Romania
}

Received 07 Jan 2020, Accepted 12 Febr 2020

hitps://doi.org/10.31688/ABMU.2020.55.1.24

\begin{abstract}
Introduction. Ischemic colitis develops due to acute reduced blood flow through the colon and appearance of secondary reperfusion injuries. Patients dependent on renal replacement therapies are at highest risk because of frequent periods of hypotension and hypoperfusion, related to haemodialysis.

Case presentation. A 66-year-old female patient, with history of stage 4 chronic kidney disease (CKD), presented for haemorrhagic shock following occult gastrointestinal bleeding and secondary acute posthaemorrhagic anaemia. Because of multiple systemic dysfunctions, she was admitted into the intensive care unit (ICU). Continuous renal replacement therapy with cytokine filter was performed, to reduce the level of circulating inflammatory markers. A computed tomography examination was performed, that established the diagnosis of ischemic colitis and she underwent subtotal colectomy with terminal ileostomy. The evolution was favourable, and after 10 days she was transferred from the ICU to the surgical ward. After another 5 days, she returned to the previous functional status and was discharged.
\end{abstract}

Résumé

Colite ischémique chez un patient atteint d'une insuffisance rénale chronique: rapport de cas

Introduction. La colite ischémique se développe en raison de la réduction aiguë du flux sanguin dans le côlon et de l'apparition de lésions de reperfusion secondaire. Les patients dépendant de thérapies de remplacement rénal sont les plus à risque en raison de périodes fréquentes d'hypotension et d'hypoperfusion liées à l'hémodialyse.

Présentation de cas. Une patiente de 66 ans, aux antécédents de maladie rénale chronique (IRC) de stade IV, a présenté un choc hémorragique à la suite d'un saignement gastro-intestinal occulte et d'une anémie post-hémorragique aiguë secondaire. En raison de multiples dysfonctionnements systémiques, elle a été admise à l'unité de soins intensifs (USI). Une thérapie de remplacement rénal continue par filtre à cytokines a été réalisée pour réduire le niveau de marqueurs inflammatoires circulants. Une tomodensitométrie a été réalisée, qui a déterminé le diagnostic de colite ischémique et elle a subi une colectomie subtotale avec 
Conclusions. Ischemic colitis can lead to lower gastrointestinal bleeding and even to haemorrhagic shock, especially in patients with chronic kidney disease, intermittent hemodialysis, atherosclerotic diseases, heart failure and diabetes mellitus.

Keywords: ischemic colitis, chronic renal failure, reperfusion, hypotension, shock.

\section{INTRODUCTION}

Ischemic colitis, the most frequent form of gastrointestinal ischemia, is a consequence of acute reduced blood flow through the colon and appearance of secondary reperfusion injuries. The duration of hypoperfusion is determinant for ischemia extension and overall outcome $\mathrm{e}^{2,3}$, patients dependent on renal replacement therapies being at the highest risk, especially due to microvascular damages and periods of hypotension in relation with haemodialysis ${ }^{4-6}$. A study conducted by Yngvadottir et $\mathrm{al}^{7}$ showed that the incidence of ischemic colitis is of 7.3 cases per 100,000 people, while Demetriou et $\mathrm{a}^{8}$ support the fact that it can affect almost 18 per 100,000 of the population. It usually presents with unspecific warning symptoms or signs, like low abdominal pain, inferior gastrointestinal bleeding, especially rectal bleeding, ileus, fever, generalized peritonitis or shock ${ }^{9}$. Del Rosario Pastor-Juan et al described that there are two important presentation forms for ischemic colitis: the gangrenous type (transmural colonic necrosis), which usually requires surgical intervention and is associated with poor outcome, and the transient form (reversible colonic lesions of mucosa or submucosa), with fewer complications, which usually responds well to conservative management ${ }^{10}$.

\section{Case presentation}

A 66-year-old female patient, with a history of stage 4 chronic kidney disease (CKD), right nephrectomy, splenectomy and type I obesity, presented for haemorrhagic shock following occult gastrointestinal bleeding and secondary acute posthaemorrhagic anaemia. She underwent upper endoscopy and colonoscopy, in the emergency department, without revealing an active site of bleeding. Because of multiple systemic dysfunctions, the patient was iléostomie terminale. Après 10 jours, elle a été transférée de l'unité de soins intensifs au département de chirurgie. L'évolution a été favorable et après 5 jours, elle a repris la condition fonctionnelle précédente at a été renvoyée à la maison.

Conclusions. La colite ischémique peut conduire à une diminution des saignements gastro-intestinaux et même à un choc hémorragique, en particulier chez les patients atteints de maladie rénale chronique, d'hémodialyse intermittente, de maladies athéromateuses, d'insuffisance cardiaque et de diabète sucré.

Mots-clés: colite ischémique, insuffisance rénale chronique, reperfusion, hypotension, choc.

admitted into the intensive care unit (ICU) and respiratory, inotropic and vasopressor supports were ensured, with multiple blood transfusions, correction of the acid-base and hydroelectrolytic disturbances. Continuous renal replacement therapy with cytokine filter was performed, to reduce the level of circulating inflammatory markers. In the second day, after bowel preparation, a new colonoscopy was performed, revealing intense swelling of the transverse and descending colon mucosa, with multiple inflammatory stenosis. The surgeon recommended a computed tomography examination, that observed a massive dilatation of ascending, transverse and descending colon and cecum (Figure 1), with important hydroaeric levels and no evidence of a distal colonic obstruction (Figure 2).

Based on the findings, surgical intervention was needed, and subtotal colectomy with terminal ileostomy were performed. The patient was extubated in the third day of ICU stay, but she needed high flow oxygen therapy for the next few days, in order to maintain a normal respiratory status. Upper endoscopy and colonoscopy were repeated in the $7^{\text {th }}$ day of hospitalisation, revealing type III hiatal hernia and extensive gastritis, for which proton pump inhibitors therapy was initiated. The continuous renal replacement therapy has stopped and the patient resumed to her three-times-weekly program of intermittent hemodialysis. The macroscopic histopathological examination revealed multiple areas of colonic adhesions and parcelar necrosis, and microscopically it was noticed total ischemic necrosis of the colonic mucosa, submucosa and submuscular layers, widespread infiltration with leukocytes and granular changes of mucosa. The patient improved over the next 10 days and she was transferred from the ICU into the surgical ward. The evolution was favourable and after another 5 days, she returned to the previous functional status and was discharged home. 


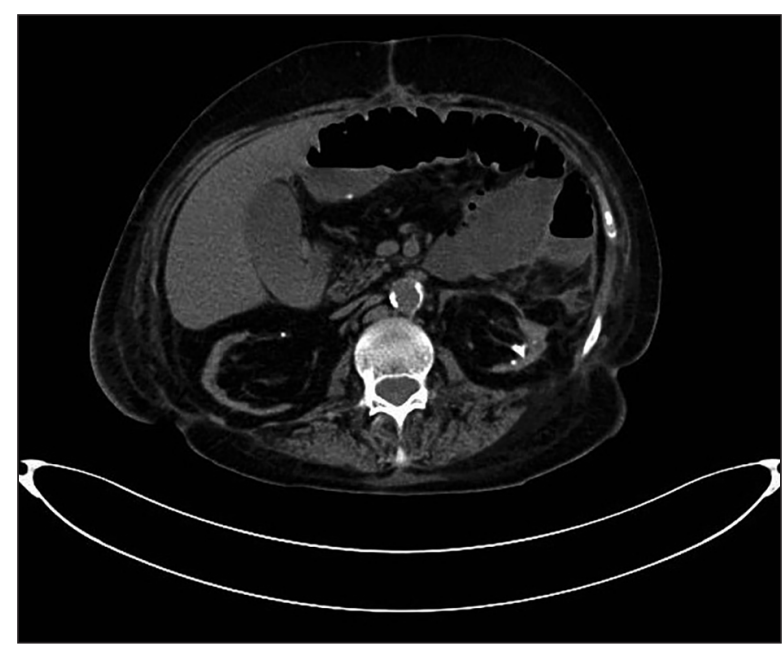

Figure 1. Computed tomography examination massive dilatation of ascending, transverse and descending colon and cecum

\section{Discussion}

Ischemic colitis associated with lower intestinal bleedings require emergency colonoscopy, in order to establish the diagnosis and to perform local hemostasis. However, like in our case, it may not always reveal the active site of bleeding, particularly if the bowel is unprepared $^{10}$. Other used diagnosis tools are abdominal echography (rarely used), computed tomography and histological examination ${ }^{11-13}$.

The main symptoms in patients with ischemic colitis are abdominal pain ${ }^{14}$, rectal bleeding (in almost $66 \%$ of patients) - its absence is a predictor for negative outcome $\mathrm{e}^{15}$, diarrhoea, nausea and vomiting $^{16}$. Cases with haemorrhagic shock are rare and usually have negative outcome ${ }^{16}$. Regarding the clinical findings, patients can present abdominal tenderness, and, in severe cases, signs of acute peritonitis (abdominal distension, guarding and severe tenderness $)^{17}$. Therefore, the triade formed by abdominal pain, tenderness and rectal bleeding represents the main presentation form ${ }^{8}$.

Our patient presented an important number of risk factors for ischemic colitis, the poor control of the kidney chronic dysfunction being the most relevant. Studies have shown that patients with chronic kidney disease have many risk factors for ischemic colitis, like peripheral vascular disease and transient periods of hypotension (especially dialysis patients) ${ }^{7}$. Other major risk factors for ischemic colitis are: female gender, age over 50 years, atherosclerotic diseases, heart failure, intermittent hemodialysis, diabetes mellitus, hypoalbuminemia, vasculitis, hypertension, anticoagulant treatment and other therapies ${ }^{2,17,18}$.

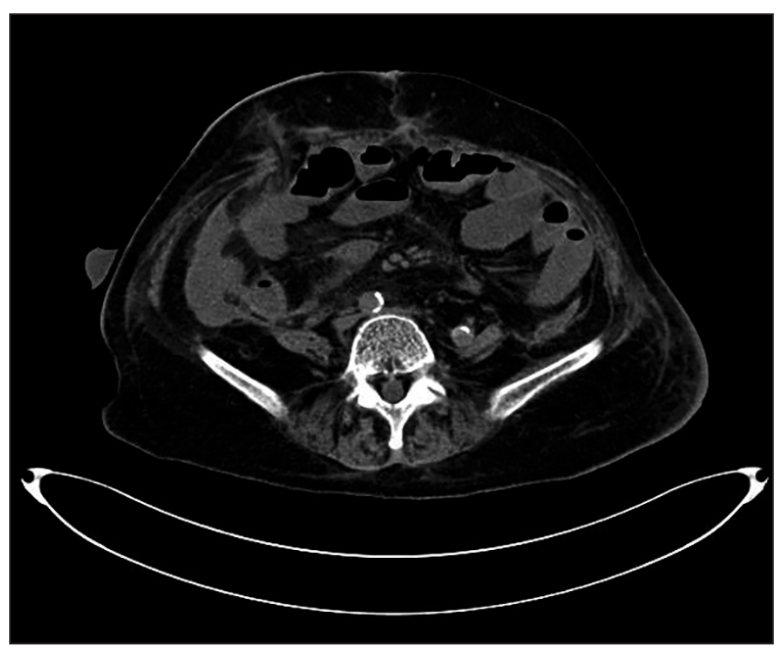

Figure 2. Computed tomography examination important hydroaeric levels without signs of distal colonic obstruction

Mortality rate is considered around $15 \%{ }^{8}$. Studies have shown that right colon ischemia or involvement of both right and left colon in patients with age over 50 years are associated with poor outcome $^{19}$. Other risk factors for mortality are concomitant small bowel ischemia, chronic respiratory disease, especially chronic obstructive pulmonary disease ${ }^{20,21}$.

Qui et al have showed in a study that ischemic colitis is the most encountered dominant histopathologic pattern of lower gastrointestinal lesions in patients with impaired kidney function, followed by infectious colitis and medication-induced colonic injury. They have concluded that colitis in patients with chronic renal disease is etiologically different from that found in people without renal dysfunction ${ }^{22}$.

\section{Conclusions}

Ischemic colitis can lead to lower gastrointestinal bleeding and even to haemorrhagic shock, especially for patients with chronic kidney disease, and in cases with extensive mucosal inflammation and ischemia, surgical intervention may be required. The major risk factors are female gender, age over 50 years, atherosclerotic diseases, heart failure, intermittent hemodialysis, diabetes mellitus and hypoalbuminemia, vasculitis, hypertension, anticoagulant and antiaggregant therapies.

\section{Author contributions}

M. T., T.H., C.B., and I.M.G. were responsible for the diagnostic procedures, clinical diagnosis, and treatment decisions. M.T. and T.P.N. wrote the manuscript. I.L., 
C.C.D., and O.G.B. critically revised the manuscript. All the authors had equal contribution to the manuscript. All authors have read and agreed to the published version of the manuscript.

\section{Compliance with Ethics Requirements:}

„The authors declare no conflict of interest regarding this article"

"The authors declare that all the procedures and experiments of this study respect the ethical standards in the Helsinki Declaration of 1975, as revised in 2008(5), as well as the national law. Informed consent was obtained from the patient included in the study"

"No funding for this study"

\section{Acknowledgments: none}

\section{References}

1. Uchida T, Matsushima M, Orihashi Y, et al. A case-control study on the risk factors for ischemic colitis. The Tokai Journal of Experimental and Clinical Medicine. 2018;43(3):111-6.

2. Trotter JM, Hunt L, Peter MB. Ischaemic colitis. BMJ. 2016;355:i6600.

3. Bodean $\mathrm{O}$, Bratu $\mathrm{O}$, Munteanu $\mathrm{O}$, et al. Iatrogenic injury of the low urinary tract in women undergoing pelvic surgical interventions. Arch Balk Med Union. 2018;53(2):281-284.

4. Kalman RS, Pedrosa MC. Evidence-based review of gastrointestinal bleeding in the chronic kidney disease patient. Seminars in Dialysis. 2015;28(1):68-74.

5. Checherita IA, David C, Stoica L, Popescu P, Ciocalteu A, Lascar I. New mediators of vascular damage in dialysed patients. Rom J Morphol Embryol. 2011;52(2):533-6.

6. Diaconescu D, Pantea Stoian A, Socea L, et al. Hepato-renal syndrome: a review. Arch Balk Med Union. 2018;53(2):239-245.

7. Yngvadottir Y, Karlsdottir BR, Hreinsson JP, et al. The incidence and outcome of ischemic colitis in a population-based setting. Scandinavian Journal of Gastroenterology. 2017;52(6-7):704-10

8. Demetriou G, Nassar A, Subramonia S. The pathophysiology, presentation and management of ischaemic colitis: a systematic review. World Journal of Surgery. 2019. doi: 10.1007/ s00268-019-05248-9

9. Feuerstadt P, Brandt LJ. Colon ischemia: recent insights and advances. Current Gastroenterology Reports. 2010;12(5):383-90.
10. Del Rosario Pastor-Juan M, Ripollés T, Martí-Bonmatí L, et al. Predictors of severity in ischemic colitis: Usefulness of early ultrasonography. European Journal of Radiology. 2017;96:21-6.

11. Romano S, Romano L, Grassi R. Multidetector row computed tomography findings from ischemia to infarction of the large bowel. European Journal of Radiology. 2007;61(3):433-41.

12. Diaconu CC, Arsene D, Balaceanu A, Bartos D. A rare tumor revealed by abdominal trauma: case presentation. Romanian Journal of Morphology and Embryology. 2014;55(3):973-976.

13. Socea B, Nica AA, Bratu O, et al. Incidental finding of a sigmoid intussusception associated with rectal prolapse - a case report. Arch Balk Med Union. 2018;53(1):143-146.

14. O'Neill S, Elder K, Harrison SJ, Yalamarthi S. Predictors of severity in ischaemic colitis. International Journal of Colorectal Disease. 2012;27(2):187-91.

15. Sun D, Wang C, Yang L, Liu M, Chen F. The predictors of the severity of ischaemic colitis: a systematic review of 2823 patients from 22 studies. Colorectal Disease. 2016;18(10):949-58.

16. Jin NC, Kim HS, Kim DH, et al. A comparison of clinical characteristics between medically treated patients and surgically treated patients with ischemic colitis. Clinical Endoscopy. 2011;44(1):38.

17. David C, Peride I, Niculae A, Constantin AM, Checherita IA. Very low protein diets supplemented with keto-analogues in ESRD pre dialysis patients and its effect on vascular stiffness and AVF Maturation. BMC Nephrology. 2016;17(1):131.

18. Montoro MA, Brandt LJ, Santolaria S, et al. Clinical patterns and outcomes of ischaemic colitis: results of the Working Group for the Study of Ischaemic Colitis in Spain (CIE study). Scandinavian Journal of Gastroenterology. 2011;46(2):236-46

19. David C, Bover J, Voiculet C, et al. Coronary risk score for mineral bone disease in chronic non-diabetic hemodialysis patients: results from a prospective pilot study. International Urology and Nephrology. 2017;49(4):689-700.

20. Moszkowicz D, Trésallet C, Mariani A, et al. Ischaemic colitis: indications, extent, and results of standardized emergency surgery. Digestive and Liver Disease. 2014;46(6):505-11.

21. Azam B, Kumar M, Mishra K, Dhibar DP. Ischemic colitis. Journal of Emergency Medicine. 2019;56(5):e85-6.

22. Qiu L, Volk E, Mais DD. Histopathologic patterns of colitis in patients with impaired renal function: a retrospective study of lower gastrointestinal tract biopsies. American Journal of Clinical Pathology. 2020;153(3):380-386. 